\title{
STRATEGI KOMUNIKASI CORPORATE SOCIAL RESPONSIBILITY (CSR) DI PT PLN (PERSERO) DISTRIBUSI JAWA TENGAH DAN DIY TAHUN 2013 - 2014
}

\author{
Shoraya Lolyta Octaviana \\ Mahasiswa Program Studi Magister Ilmu Komunikasi FISIP Undip Angkatan VI \\ Email : shoraya_han@yahoo.com
}

\begin{abstract}
:
Corporate social responsibility has become a global issue in the community and the company. CSR programs conducted by PT PLN (Persero) Distribution Regional Central Java and Yogyakarta in the areas specially for Education, Health, Community Empowerment and Environmental Conservation has been right on target. Corporate Social Responsibility program targets, among others, that people are more concerned with the condition of the PLN, and for good imaging PLN by society. Communication strategy to the public that are used in the dissemination using print media such as newspapers and magazines nationally and locally. Electronic media using television and radio in Central Java and Yogyakarta and national, also use social media such as Facebook and Twitter.
\end{abstract}

Keywords : Strategic Communication, Corporate Social Responsibility.

\section{Pendahuluan}

Akhir - akhir ini kerap terjadi kecelakaan dan gangguan kelistrikan yang disebabkan oleh kalangan masyarakat atau pelanggan PLN, sehingga menimbulkan persepsi buruk tentang kualitas pelayanan PLN di kalangan masyarakat. Dengan era yang semakin maju dengan segala perkembangan di seluruh sektor kehidupan baik dalam sektor politik, ekonomi maupun sosial budaya membawa masyarakat untuk menghadapi persaingan ketat. Krisis moneter yang terjadi pada awal tahun 1998 mengakibatkan kondisi sosial ekonomi Indonesia mengalami gejolak sehingga tingkat kemiskinan semakin tinggi. Berdasarkan data yang terakhir dikeluarkan oleh Human Development Report tahun 2003 menunjukan bahwa Indonesia berada dalam index peringkat 112 dari 175 negara - negara miskin yang ada di dunia. (Buditama, Prasetijo dan Rudito, 2004)

Kondisi tersebut membawa kesadaran bahwa penanganan masalah nasional ini tidak cukup hanya diperhatikan pemerintah namun sebagian dari negara Indonesia maka seluruh komponen masyarakat perlu berpartisipasi dalam pembangunan. Corporate Sosial Responsibility (CSR) yang di artikan sebagai tanggungjawab sosial perusahaan merupakan paradigma baru yang memandang perusahaan sebagai bagian dalam masyarakat itu sendiri. Perusahaan dipandang sebagai suatu komunitas yang akan selalu mempunyai hubungan sosial dengan komunitas yang lainnya. Dalam paradigma ini kepedulian pihak perusahaan akan selalu dipertanyakan sebab telah menjadi bagian masyarakat yang lebih luas dimana apapun yang terjadi pada masyarakat, akan mempengaruhi perusahaan dan sebaliknya.

Masyarakat menjadi semakin kritis dan mampu melakukan filterisasi terhadap dunia usaha yang tengah berkembang di tengah masyarakat ini. Hal ini menuntut pelaku bisnis untuk menjalankan usahanya dengan semakin bertanggungjawab. Pelaku bisnis tidak hanya di tuntut untuk memperoleh capital again atau profit dari lapangan usahanya, melainkan mereka juga diminta untuk memberi konstribusi baik secara materiil, spiritual, dan aturan sosial kepada masyarakat dan pemerintah. 
Masyarakat kita bukanlah masyarakat yang masih dapat dibodohi oleh sisi eksternal perusahaan, masyarakat kita saat ini lebih kritis dan peka terhadap kinerja dan kontribusi perusahaan terhadap dunia luar. Masalahnya selain rumit ketika tetap saja para pelaku dan investor berpijak pada stereotip bahwa CSR tidak profitable, tidak berdampak langsung terhadap peningkatan pendapatan perusahaan. Mereka cenderung ingin yang instan, langsung mendapat profit yang besar, tanpa peduli terhadap masalah - masalah eksternal perusahaan.

Selain itu, investor juga terlalu menginginkan realisasi investasi mereka untuk sektor riil dalam artian benar - benar berdampak langsung terhadap peningkatan pendapatan. Padahal, CSR memiliki dimensi yang jauh lebih rumit dan kompleks dari sekedar analisis laba rugi. Pengenalan terhadap budaya setempat atau analisis terhadap need assessment semestinya menjadi hak krusial yang mesti dilakukan. Poin inilah yang terkadang menyebabkan perbedaan kepentingan, sehingga dunia usaha terkadang merasa program CSR bukanlah kompetensi mereka.

Paradigma mengenai kontribusi pajak perusahaan terhadap negara semakin menambah runyam hal ini. Ada beberapa kalangan yang menilai jika masalah sosial hanya merupakan tanggungjawab negara saja, dunia usaha cukup membayar pajak untuk memberi konstribusi terhadap masyarakat. Pemikiran ini sudah tidak relevan, justru perusahaan yang akan memenangkan kompetensi global adalah perusahaan yang memiliki kemampuan Public Relations (PR) yang baik, salah satunya dapat dicapai dengan mencanangkan program CSR yang terintregasi sebagai standar kebijakan dan strategi bisnis mereka.

Lagipula, dengan adanya anggapan bahwa dunia usaha merupakan bagian yang terintregasi dalam masyarakat, sudah sepatutnya jika dunia usaha berkewajiban untuk membantu menyelesaikan masalah sosial yang ada dalam kehidupan bermasyarakat. Selain itu, semestinya dunia usaha tidak menganggap dunia CSR sebagai kewajiban yang memaksa, akan tetapi 34 sebagai refleksi dari tuntutan masyarakat terhadap dunia usaha yang jika tidak dilakukan akan berdampak adanya bentuk kegiatan represif dan anarkisme dari masyarakat. Tanggungjawab sosial perusahaan atau CSR sendiri adalah suatu konsep bahwa organisasi (bukan hanya perusahaan saja) memiliki suatu tanggungjawab terhadap konsumen, karyawan, pemegang saham, komunitas dan lingkungan sekitarnya dalam segala aspek operasional perusahaan.

Magnan dan Ferrel dalam (A.B Susanto, 2007 : 21-25) menyatakan bahwa CSR dimaknai sebagai " $A$ bussiness acts in socially responsible manner when its decision and account for and balance diverse stake holder interest".

Pengertian dari pernyataan Magnan dan Ferrel menekankan pada perlunya memberikan perhatian secara seimbang terhadap kepentingan para stakeholdersnya yang bermacam - macam dalam setiap pengambilan keputusan. Sebuah bisnis bertindak secara bertanggung jawab sosial terhadap karyawan dan masyarakat, tanggungjawab terhadap lingkungan juga tidak kalah pentingnya.

Elkington dalam (A.B Susanto, 2007 : 21-25) mengemukakan bahwa sebuah perusahaan yang menunjukkan tanggungjawab sosialnya akan memberikan perhatiannya kepada peningkatan kualitas perusahaan (profit) masyarakat, khususnya komunitas sekitar (people), serta lingkungan hidup (the earth).

Menurut (Michael Hopkins, 2003) pengertian CSR adalah "CSR is concerned with treating the stakeholders of the firm ethically or in responsible manner".

Michael Hopkins memaparkan bahwa CSR itu berkaitan dengan bagaimana memperlakukan para stakeholder perusahaan secara etis dan bertanggungjawab. Secara umum CSR untuk peningkatan kualitas kehidupan dan menanggapi keadaan sosial yang ada.

Pengertian CSR menurut Philip Kotler dan Nancy Lee, CSR merupakan sebuah komitmen perusahaan untuk memajukan komunitas melalui praktek bisnis dan memberikan kontribusi dari sumber daya perusahaan itu sendiri yang 
dilakukan melalui penilaian yang baik. (Kotler \& Lee, $2005: 3$ )

PT PLN (Persero) merupakan salah satu perusahaan BUMN besar di Indonesia yang wajib menerapkan Corporate Social Responsibility (CSR). Berdasarkan Undang - undang No. 40 Tahun 2007 tentang Penanaman Modal, pasal 15 butir b menyatakan bahwa "setiap penanam modal berkewajiban melaksanakan tanggungjawab sosial perusahaan". Program - programnya sebagai wujud kepedulian perusahaan terhadap perkembangan masyarakat Indonesia ke arah yang lebih baik. Dibentuknya seksi CSR pada bagian Hubungan Masyarakat (Humas) secara terstruktur menunjukkan keseriusan PT Pertamina dalam menjalankan program Corperate Social Responsibility.

Seperti yang di ungkapkan oleh (Iriantara, 2004 : 85), program Corporate Social Responsibility perusahaan di tuntut untuk lebih bersifat strategis karena program ini bukan lagi penyangga antara organisasi dan lingkungannya, melainkan menjalankan fungsi yang mesti mengintegrasikan kepentingan - kepentingan stakeholder, khususnya karyawan dan komunitas, kedalam kepentingan organisasi. Oleh karena itu maka diperlukan strategi komunikasi yang terencana dengan baik agar program tersebut mendapat dukungan penuh dan partisipasi dari karyawan perusahaan bahkan masyarakat.

\section{Metodologi Penelitian}

Jenis penelitian yang digunakan dalam penelitian ini adalah penelitian deskriptif kualitatif (Moleong, 2005) yaitu peneliti harus dapat mengetahui kedudukannya pada saat pengumpulan data dilapangan. Peneliti dalam penelitian deskriptif kualitatif bertindak sebagai alat pengumpul dan penafsir data. Hal tersebut dilakukan karena jika memanfaatkan alat yang bukan manusia dan mempersiapkan dirinya terlebih dahulu sebagai yang lazim digunakan dalam penelitian klasik, maka sangat tidak mungkin untuk mengadakan penyesuaian terhadap kenyataan dilapangan.

Metode penelitian kualitatif deskriptif merupakan metode penelitian yang dilakukan untuk mengetahui nilai variabel mandiri atau lebih (independen) tanpa membuat perbandingan atau menggabungkan antara variabel satu dengan yang lain (Sugiyono, 2012 : 13). Metode deskriptif dapat disimpulkan sebagai sebuah metode yang bertujuan untuk melukiskan atau menggambarkan keadaan dilapangan secara sistematis dengan fakta - fakta dan interpretasi yang tepat, datanya saling berhubungan, serta bukan hanya untuk mencari kebenaran mutlak tetapi pada hakekatnya mencarai pemahaman observasi.

Penelitian ini dilakukan di Kota Semarang, sedangkan untuk teknik pengumpulan datanya, peneliti menggunakan wawancara mendalam. Maksudnya adalah peneliti mencari data dengan mewawancarai secara mendalam narasumber yang berkaitan dengan Strategi Komunikasi CSR pada PT PLN (Persero) Distribusi Jawa Tengah dan DIY, yaitu dengan Kepala Bagian Humas Supriyono, bagian CSR Sri Wahyuningsih, staff humas Iwan Setiawan dan Dimas Satria.

Penelitian ini menggunakan teknik pemeriksaan keabsahan data teknik trianggulasi seperti yang di nyatakan (Moleong, 2005) yaitu teknik pemeriksaan keabsahan data yang memanfaatkan sesuatu yang lain. Metode trianggulasi yang digunakan adalah Metode Trianggulasi Sumber, yaitu untuk menguji kredibilitas data dilakukan dengan cara mengecek data yang telah di peroleh dari beberapa sumber.

\section{Pembahasan}

\section{PT PLN (Persero) Distribusi Jawa Tengah dan DIY}

Pada tanggal 27 Desember 1958 di keluarkan Undang - undang No. 86 tentang Nasionalisasi semua perusahaan Belanda dan PP No. 18 Tahun 1958 tentang perubahan Djawatan Listrik dan Gas Negara menjadi Perusahaan Listrik Negara (PLN). Berdasarkan Peraturan Pemerintah No. 23 Th. 1992 dan akta 
Notaris Sutjipto, SH No. 69 th. 1994 di Jakarta status PLN berubah menjadi PT. Perusahaan Listrik Negara (Persero).

PLN distribusi Jateng \& DIY merupakan BUMN yang membentuk perseroan terbatas, sahamnya sebagian besar dimiliki oleh pemerintah. Perusahaan ini bergerak dalam bidang jasa pelayanan masyarakat di bidang kelistrikan yang meliputi penjualan rekening, listrik prabayar, pasang baru, tambah daya, penyisiran tarif dan Penerbitan Pemakaian Tenaga Listrik (P2TL). (Sumber : Company Profile PT PLN (Persero) Distribusi Jateng dan DIY)

2. Corporate Social Responsibility (CSR) PT PLN (Persero) Distribusi Jawa Tengah dan DIY Tahun 2013 - 2014

Wilayah dan sasaran program CSR yaitu Ring I (stakeholder yang terkena dampak langsung kegiatan operasi perusahaan berada disekitar Kantor Unit / lokasi), Ring II (stakeholder yang terkena dampak tidak langsung kegiatan operasi perusahaan berada di Kota / Kabupaten yang sama dengan Kantor Unit / Lokasi), Ring III (stakeholder yang berada diwilayah kerja operasi perusahaan diluar ring I dan ring II berada di provinsi yang sama dengan Kantor Unit / Lokasi). PLN distribusi Jawa Tengah dan DIY sebagai koordinator provinsi membawahi PLN unit - unit induk yang ada di wilayah Jawa Tengah dan DIY.

3. Strategi Komunikasi Corporate Social Responsibility (CSR) di PT PLN (Persero) Distribusi Jawa Tengah dan DIY Tahun 2013 - 2014

Strategi yang digunakan oleh PLN dalam mempublikasi program - program CSR kepada masyarakat menggunakan media cetak dan media elektronik. Contohnya pada program bedah rumah di Kelurahan Bandarharjo Semarang, PLN bekerja sama dengan Harian Suara Merdeka, PLN memilih media yang berpengaruh di Jawa Tengah dan DIY untuk bekerjasama dikarenakan target pemberitaannya sampai ke khalayak umum.

Strategi komunikasi yang dilakukan masing - masing program berbeda karena tergantung dengan sasaran program, divisi External Relations melakukan komunikasi dengan pihak eksternal dengan melalui press conference dan memberikan press release kepada semua media cetak yang dianggap berpengaruh di wilayahnya.

Berikut adalah media - media yang bekerjasama dengan PLN dalam sosialisasi program CSR ke masyarakat dan stakeholdernya. Media cetak nasional yang digunakan yaitu Kompas, Media Indonesia, Bisnis Indonesia, Jawa Pos, Koran tempo dan Majalah Tempo. Media cetak lokal yang digunakan meliputi Kedaulatan Rakyat, Suara Merdeka, Radar Semarang, Radar Tegal, Radar Purwokerto, Wawasan, Harian Semarang, Jateng Pos, Yogyakarta Pos, Solo Pos dan Warta Jateng. PLN bekerjasama dengan TV lokal maupun nasional seperti Metro TV, Trans TV, SCTV, TV one, Cakra TV, TVRI Jateng, TVRI Jogja, Pro TV, TA TV Solo, Borobudur TV dan TV KU. Untuk Radionya PLN bekerjasama dengan hampir seluruh radio di Jawa Tengah dan DIY untuk sosialisasi CSR seperti radio RRI pusat, RRI Jawa Tengah, Gajahmada Fm, Damashinta Pekalongan, Radio Idola, Trax Fm, Sonora Semarang, Solo Fm, Sonora Yogyakarta dan lain sebagainya. Menurut teori (Jefkins, 1992) mengenai media PR hal ini sesuai dengan pilihan media yang digunakan External Relation (Humas) yang berlandaskan berbagai tujuan dan jenis sasaran khalayak.

Selain itu PLN mengadakan program press tour yaitu mengajak beberapa media ketempat - tempat seperti ke mitra - mitra binaan PLN distribusi dan ke instalasi listrik seperti pembangkitan di Tanjung Jati Jepara, PLTA Mrica Wonosobo, Gardu Induk Ungaran dan Pedan Klaten serta ke kantor rayon - rayon di wilatah kerja distribusi dan DIY. Kegiatan press tour 
ini bertujuan untuk menginformasikan kepada khalayak proses pembangkitan listrik sampai di distribusikan kerumah rumah dan tujuannya agar masyarakat bisa menghemat energi listrik. Tujuan CSR dalam kegiatan ini berupa pencitraan atau membangun brand image perusahaan di mata stakeholder.

PLN menggunakan intern media untuk sosialisasi program CSR diantaranya intranet yaitu media publikasi berita atau artikel yang disampaikan melalui http:// intranet.pln untuk mengkomunikasikan program - program CSR dengan karyawannya karena ini merupakan media internal yang bisa di akses seluruh karyawan. Media cetak Pinisi yang terbit mingguan di majalah tersebut terdapat dua halaman khusus meliput kegiatan CSR PLN Jateng dan DIY. Ada juga PLN TV untuk publikasi kegiatan CSR secara nasional. Seperti yang di utarakan (Effendy, 2004) strategi komunikasi yang mempertimbangkan komunikator dan pemilihan media yang disesuaikan dengan tujuan pesan komunikasi serta sasaran komunikasi sesuai dengan teori korelasi antar komponen dalam strategi komunikasi.

Setiap karyawan PLN seharusnya mengetahui program CSR karena informasi dari TV Display yang berada di lobby Kantor PLN, di jalan kantor yang strategis dengan menyajikan program - program PLN termasuk CSR didalamnya. Hampir semua program CSR dikomunikasikan ke publik melalui press release dan pada saat melakukan komunikasi perlu memperhatikan sasaran komunikasinya. Setelah itu memilih media yang sesuai dengan sasaran komunikasi tersebut.

PLN memiliki kepentingan untuk membina hubungan baik, saling pengertian, dan semangat kerjasama sehingga nama baik dan legimitasi perusahaan tetap terjaga. PT PLN (Persero) juga memiliki strategi yang bagus dan tepat dengan melakukan berbagai upaya untuk pemberdayaan potensi masyarakat di lingkungan kegiatan usaha PLN dan PLN berkomitmen untuk mendukung perkembangan masyarakat Jawa Tengah dan DIY khususnya lewat program - program CSR nya.

Melalui program CSR nya PLN ingin melakukan perubahan untuk semakin dipercaya masyarakat melalui dedikasi yang tinggi serta memegang teguh komitmen untuk melakukan pemberdayaan potensi masyarakat yang berada di lingkungan kegiatan perusahaan. Untuk PT PLN (Persero) Dstribusi Jawa Tengah dan DIY, hasil perubahan ini mulai tampak, dapat kita lihat dari respon masyarakat yang antusias untuk mengikuti seluruh program CSR yang ada di PLN dan hubungan harmonis yang terjalin antara masyarakat dan seluruh staff dan karyawan PT PLN tentunya melalui strategi - strategi komunikasi yang sudah dijalankan.

\section{Program - Program CSR dan Pembahasan}

CSR yang sebagai program PLN, sudah dijalankan sejak tahun 1993. Corporate Social Responsibility merupakan suatu bentuk tanggungjawab sosial perusahaan serta komitmen perusahaan untuk memberi kontribusinyata pada peningkatan ekonomi dankualitas hidup pekerja dan keluarganya, di samping komunitas lokal dan serta masyarakat keseluruhan. CSR dilakukan perusahaan untuk mempertahankan image positif di mata stakeholdernya. Dibagian External Relation, terdapat satu divisi yang menjalankan dan bertanggungjawab dengan program CSR di bawahi oleh Sri Wahyuningsih. Di PLN terdapat empat program yang menjadi fokus CSR antara lain bidang kesehatan, lingkungan, pemberdayaan masyarakat dan konservasi lingkungan.

CSR bisa dijalankan melalui prosedur prosedur yang harus dilewati, antara lain pihak ke-III mengajukan surat permohonan 
kepada perusahaan melalui GM atau Manajer Area yang ada diwilayah kerja distribusi Jawa Tengah dan DIY. Kebutuhan CSR bisa juga datang dari internal perusahaan berupa proposal hasil penelitian strategis berdasarkan sosial mapping. Surat atau hasil penelitian strategis diterima GM, selanjutnya GM memberikan disposisi kepada Humas. Surat yang diterima melalui Kepala PLN Area diteruskan ke Humas. Humas membuat kajian kelayakan dan pembebanan anggaran. Terhadap permohonan yang diputuskan tidak layak dipenuhi, disampaikan surat balasan yang ditandatangani oleh Humas. Apabila layak, Humas membuat kajian pembebanan anggaran apakah menggunakan anggaran CSR atau PKBL. GM memberikan persetujuan dan meneruskan kepada Humas. Humas memproses keuangannya melalui Fungsi Keuangan berdasarkan persetujuan GM.

\section{Program - Program :}

\section{a. Kesehatan}

Di bidang kesehatan pada tanggal 18 Oktober 2013 PLN melaksanakan program kegiatan CSR "Penyuluhan Pola Hidup Bersih dan Sehat di Desa Plumutan Salatiga". Dalam kegiatan ini, PLN mendatangkan dokter dari Kota Salatiga dan tim CSR dari PLN Distribusi Jateng dan DIY. Bentuk kegiatannya memberikan penyuluhan bagaimana melakukan pola sehat terhadap anak - anak dengan langkah $3 \mathrm{M}$ yaitu menggosok gigi, mencuci tangan dan makan makanan sehat dan bergizi. Di ambil sekolahan yang sangat tertinggal di Kota Salatiga dengan jumlah peserta 60 (enampuluh) anak. Disini PLN memberikan bantuan 12 (dua belas) paket obat - obatan dan tempat obatnya, juga memberikan 12 poster acrilyc 3M yang akan di letakkan di masing - masing kelas sekolah tersebut. Selain itu juga memberikan bantuan tempat sampah tertutup yang terdiri dari tempat sampah organik dan an organik di masing - masing kelas.

Masih di tahun 2013 PLN kembali melakukan kegiatan CSR dalam bidang kesehatan dengan memberikan bantuan fasilitas kesehatan di desa Gerbosari Yogyakarta pada tanggal 30 Desember 2013. Bantuan berupa 1 buah genset yang akan digunakan di Pos Kesehatan Desa (Poskedes) karena di Poskedes tersebut juga mempunyai ruang bersalin yang mana genset akan sangat membantu dalam proses bersalin Ibu. Selain itu juga memberikan bantuan alat tensi darah dan alat cek diabetes pada 4 dukuh di desa tersebut. Masing - masing bantuan alat kesehatan diberi sticker PLN dengan tujuan agar masyarakat senantiasa ingat dengan kegiatan CSR dari PLN.

\section{b. Pendidikan}

PLN memiliki kegiatan CSR dibidang pendidikan yaitu pengadaan PLTS untuk Lab Fisika di SMAN 3 Yogyakarta, membuat empat tugu panel kecil di halaman sekolah dengan tujuan menghemat biaya listrik sekolahan karena panel tersebut bisa digunakan untuk fasilitas siswa re-charge laptop ataupun ponselnya. Memberikan bantuan lampu sangat hemat energi (sehn) sebesar $500 \mathrm{Wp}$ (watt-peak), kegiatan tersebut di resmikan pada tanggal 21 November 2014.

\section{c. Konservasi Lingkungan}

Program CSR PT PLN (Persero) Distribusi Jawa Tengah \& DIY sebagai wujud kepedulian terhadap lingkungan, pada tanggal 17 Desember 2014 menanam 10.000 mangrove di wilayah tepi pantai Sabetan Desa Wedung Kabupaten Demak. Dipilihnya daerah tersebut dalam aksi peduli lingkungan karena hampir 70 hektare wilayah tepi pantainya mengalami abrasi. Selain penanaman mangrove secara simbolis oleh para tamu undangan, dari PLN Pusat dan PLN Distribusi, tim CSR juga melakukan sosialisasi tentang 
penanaman dan manfaat mangrove bagi kelestarian pantai. Tujuan dari kegiatan ini selain menyelamatkan daerah pesisir dari abrasi, juga untuk memberikan nilai edukasi kepada generasi muda mengenai kelistrikan dan pentingnya menghijaukan bumi untuk mengatasi pemanasan global maupun mengurangi emisi karbon.

Pemahaman terhadap pola kehidupan masyarakat yang ada disekitar korporat sekaligus juga dapat memahami stakeholder yang ada dan tumbuh di lingkungan korporat dan masyarakat sesuai dengan teori (Budimanta, Prasetijo dan Rudito, 2004).

\section{d. Pemberdayaan Masyarakat}

Dalam rangka pengentasan kemiskinan yang menjadi salah satu program pemerintah, salah satu program unggulan CSR dari PLN Distribusi Jateng DIY yaitu bedah dan renovasi rumah yang dilaksanakan di kelurahan Bandarharjo Semarang. Adapun yang sudah di renovasi oleh PLN sebanyak 7 rumah yang memang tidak layak huni. Dengan memberikan anggaran 1 rumah sebesar Rp 15.000.000,dan dibantu oleh warga setempat dalam jangka waktu bukan oktober 2014 sampai selesai menjadikan tujuh rumah tersebut layak dihuni oleh pemilik sebelumnya.

Strategi komunikasi yang dilakukan oleh Kehumasan PLN berupa sosialisasi ke pemda dan masyarakat setempat, memberikan press release media, media elektronik yang digunakan antara lain untuk TV ada TVRI Jateng, TV KU, Pro TV, Metro TV. Radio yang bekerjasama dengan event ini Radio Sonora dan RRI Jateng sedangkan media cetaknya Suara Merdeka, Warta Jateng, Bisnis Indonesia, Radar Semarang dan Kedaulatan Rakyat. Sasaran komunikasi dari program ini adalah orang dewasa yang mana sesuai dengan teori korelasi antar komponen menurut (Effendi, 2004).

\section{e. Program Kemitraan}

Program kemitraan merupakan program untuk meningkatkan kemampuan usaha kecil agar menjadi tangguh dan mandiri melalui pemanfaatan dana yang berasal dari bagian laba BUMN. Pelaksanaan PK umumnya dilakukan melalui pembinaan secara struktural oleh PLN langsung pada mitra binaan yang pada dasarna dilakukan melalui beberappa tahap : melakukan survey penelitian lapangan ataa permohonan bantuan dari calon mitra binaan, melalukan pembinaan kemitraan berupa bantuan modal kerja dan membuat laporan secara periodik.

rogram Kemitraan PLN di Desa Popongan Salatiga yang diresmikan pada tanggal 7 November 2013 berupa bantuan pembuatan makanan kecil yang diharapkan sangat bermanfaat dalam meningkatkan produktifitas, penyerapan tenaga kerja dan penyerapan produksi atau hasil panen masyarakat sekitar. Industri rumahan yang dibantu yaitu pembuatan stik ubi, stik bawang dan kencok ubi dengan Rumini sebagai pemilik usahanya.

\section{Penutup}

Corporate Social Responsibility adalah komitmen perusahaan untuk memberi kontribusi nyata pada peningkatan ekonomi dan kualitas hidup pekerja dan keluarganya, di samping komunitas lokal dan serta masyarakat keseluruan. CSR dilakukan perusahaan untuk mempertahankan image positif di mata stakeholdernya. Sasaran program Corporate Social Responsibility antara lain kepedulian terhadap pelanggan PLN, menjaga aset- aset yang ada di lingkungan masyarahat, agar masyarakat membayar rekening listrik tepat waktu. Mengetahui produk - produk PLN seperti listrik pintar, call center 123 dan sebagainya.

Dalam mengkomunikasikan program Corporate Social Responsibility PT PLN (Persero) Distribusi Jawa Tengah dan DIY menggunakan strategi media yang untuk 
sosialisasi program Corporate Social Responsibility kepada masyarakat terbagi menjadi dua macam yaitu ekstern media dan intern media.

\section{Daftar Pustaka}

Budimanta, Arif, Bambang Rudito, \& Adi Prasetijo. (2004). Corporate Social Responsibility : Jawaban Bagi Model Pembangunan Indonesia Masa Kini. Jakarta: Indonesian Center for Sustainable Development

Effendy, Onong Uchjana. (2004). Dinamika Komunikasi. Bandung: PT Remaja Rosdakarya

Hopkins, Michael. (2003). The Planetary Bargain, Corporate Social Responsibility Matters. London: Earthscan Publications Ltd.

Iriantara, Yosal. (2004). Community Relations : Konsep dan Aplikasinya. Bandung: Sambiosa Rekatama Media

Kotler, Philip., \& Nancy Lee. (2005). Corporate Social Responsibility : Doing The Most
Good for Your Company and Your Cause. New Jersey: John Willey \& Sons Littlejohn, Stephen W. \& Karen A. Foss. (2009). Teori Komunikasi (Theories of Human Communication) : Edisi 9. Jakarta : Salemba Humanika

Moleong, Lexy J. (2007). Metode Penelitian Kualitatif. Bandung: PT Remaja Rosdakarya

Sugiyono. (2005). Memahami Penelitian Kualitatif. Bandung : CV Alfabeta (2012). Metode Penelitian Pendidikan (Kualitatif, Kuantitatif dan $R \& D)$. Bandung : CV Alfabeta

Susanto, A.B. (2007). A Strategic Management Approach Corporate Social Responsibility. Jakarta: The Jakarta Conculting Group

\section{Undang - Undang :}

Undang - Undang Republik Indonesia Nomor 40 Tahun 2007 tentang Perseroan Terbatas 